REVISTA DE DERECHO UNED, NÚM. 9, 2011

\title{
LA POLÍTICA SOCIAL A FAVOR DE LOS CIUDADANOS. LA ECONOMÍA ESPECULATIVA UNA AMENAZA AL ESTADO DE BIENESTAR SOCIAL
}

\author{
Pedro Fernández Santiago \\ Profesor Contratado Doctor de Servicios Sociales y Dependencia y \\ Política Social. Departamento de Servicios Sociales y Fundamentos \\ Históricos Jurídicos. Facultad de Derecho. UNED
}

Resumen: Esta crisis financiera y de confianza que se está produciendo en un mundo globalizado y como consecuencia más interdependiente, que aboca a los Estados a financiar y volver a reflotar a quienes nos sumergieron en ella, no puede ni debe ser la coartada para desmantelar el Estado de Bienestar de los países occidentales ni seguir produciendo la muerte, el hambre y la miseria de millones de personas, del mismo modo, la inacción de las grandes instituciones mundiales y agentes políticos está abocando a que esta crisis se alargue en el tiempo y haga renacer reivindicaciones que en algunos casos pueden convertirse en violentas, situación que hasta el momento no se está produciendo.

Palabras clave: Crisis financiera, crisis de confianza, estado de bienestar, política social, mercado, consumo.

Abstract: This financial and reliable crisis that there are producing in a globalized world and like a interdependent consequence, which brought about the States to revive and finance again who immersed us in it, it can't and mustn't be the reason to dismantle the Welfare State of the occidental countries, and no longer to produce death, hunger and misery of million people.

In the same way the non actions of the large global institutions 
and political agents are helping that this crisis is prolonged in the time and this makes claims to be born which in some cases may be violent, but this is a situation that so far there hasn't been happened.

Key words: financial crisis, reliable crisis, welfare state, social politic, market, consumption.

Sumario: I. Introducción.-II. Tambalear países, sueños y personas.-III. Darwinismo social, antítesis de las políticas de bienestar social.-IV. Política social y crisis de bienestar social.-V. La incertidumbre ante una interpretación teórica conservadora de la crisis.-VI. Respuesta ante la crisis. Políticas sociales activas en bienestar social.-VII. Conclusiones.-VIII. Bibliografía.

\section{INTRODUCCIÓN}

Cada concepción de la naturaleza humana conlleva una visión propia de las necesidades del ser humano, y por tanto, de la forma de hacer frente a las mismas. La incapacidad del mercado de resolver de forma satisfactoria las cuestiones que afectan a estas necesidades, da paso a la creación de una acción pública orientada a corregir el reparto de renta producto del mercado, es decir, se manifiesta la necesidad de una política redistributiva.

Keynes define la Teoría Económica como un método más que una doctrina, una disciplina de la mente, una técnica de pensar que ayuda a las personas que tienen que sacar conclusiones. Economía ${ }^{1}$ podría definirse como: la ciencia que estudia la asignación más conveniente de los recursos escasos de una sociedad para la obtención de un conjunto ordenado de objetivos.

Todo producto o servicio conlleva un precio, estos fluctúan en función de diversos factores y contextos, y en base a estos, a las actividades financieras y/o operaciones comerciales que tienen por objeto la obtención de un beneficio económico de ellos, se las denomina especulación, dado que lo que pretenden estas actividades no es disfrutar de un bien o servicio, sino obtener un beneficio en base a las fluctuaciones de los precios de los mismos. En la actualidad estamos sintiendo sobre nuestras maltrechas economías una actividad especulativa que no conlleva ninguna obligación, ni siquiera con la gestión de bienes en los que se invierte, limitándose exclusivamente al movimiento de capitales.

1 Mochón, F., Economía teoría y política, McGraw-Hill, Madrid, 1995. 
La producción de bienes y servicios y la actividad comercial que esto conlleva genera empleos. El empleo fomenta los salarios reales, que a su vez estimulan el consumo de productos y provoca que la economía genere más empleos y en consecuencia menos pobreza. El empleo podrá ser potenciado cuando se tomen las medidas necesarias para evitar la especulación que ahoga en estos momentos a la economía occidental.

Desde los años setenta se ha producido un gran cambio potenciado por las tecnologías de la información y la comunicación, así como por la revolución digital. Las autopistas de comunicación, con internet a la cabeza, hacen que se produzca un intenso impulso e intensificación de los intercambios, como resultado de todo ello se permite a los agentes económicos el intercambio de activos financieros, y su consecuencia es la potenciación de los mercados financieros, en cuya base está la función de establecer los mecanismos que posibiliten el contacto entre los participantes en la negociación, fijar los precios de los productos financieros en función de su oferta y su demanda, reduciendo los costes de intermediación, lo que permite una mayor circulación de los productos y la administración de los flujos de liquidez de productos de un mercado a otro.

En los momentos actuales podríamos situar la crisis ${ }^{2}$ no como el resultado inevitable de la inestabilidad propia de los mercados financieros desregulados, sino como el efecto de la falta de honradez y de la irresponsabilidad de algunos agentes financieros mal controlados por los poderes públicos (...) La integración financiera ha llevado a las finanzas al cenit de su poder por haber unificado y centralizado la propiedad capitalista a escala mundial. Desde este momento, son ellas las que determinan las normas de rentabilidad exigidas a todo capital. El proyecto era que los mercados financieros sustituyeran en materia de inversiones a la financiación bancaria. Pero este proyecto ha fracasado, puesto que hoy globalmente, son las empresas las que financian a los accionistas, y no al contrario.

La actividad especulativa también conlleva riesgos para el especulador, posiblemente algún tipo de especulación sea imposible e incluso negativo evitar, en lo que se debería intervenir es sobre la especulación de las grandes corporaciones de intereses que son capaces de arrastrar al abismo de la miseria a países enteros. En muchos casos hemos visto a los políticos, referentes ideológicos de dichas cor-

2 Askenazy, P.; COUTROR, T.; OrléAn, A.; SterdyniaK, H., Manifiesto de economistas aterrados. Madrid, 2011. 
poraciones, mirar para otro lado mientras dicen estar tomando medidas para paliar esa situación. Posiblemente la única forma de evitar la especulación desmedida es a través de la regulación de los mercados y la competencia, mientras más proponentes, precios más bajos. Los controles de precios crean desabastecimiento y cierre de empresas productoras, monopolizando aun más el mercado, estimulando así, la especulación desmedida.

\section{TAMBALEAR PAÍSES, SUEÑOS Y PERSONAS}

"Cuando la especulación arrecia, no hay banco central que aguante la sangría de divisas ${ }^{3}$. El 17 de septiembre de 1992, el ministro de Economía Carlos Solchaga tuvo que explicar en el Congreso la situación que le había llevado a llamar a la puerta de Bruselas y discutir durante horas hasta lograr un acuerdo para devaluar la peseta. Fue al día siguiente de un miércoles negro con un parte de guerra desolador: la peseta, devaluada; la libra esterlina y la lira italiana, fuera del Sistema Monetario Europeo (SME), y una grieta en el proyecto de la Europa económica. La peseta se devaluó dos veces más en los meses siguientes y una cuarta, la última de la historia, en 1995.

Siguiendo con el artículo de esta autora "Con este caldo de cultivo, el inversor de origen húngaro George Soros llegó a vender más de 10.000 millones de libras esterlinas y forzó la devaluación de la moneda en aquel miércoles del 16 de septiembre, en el que ganó 1.000 millones de dólares. Mientras fraguaba la operación, anunció públicamente que la libra perdería valor, una legión de inversores le emuló y, efectivamente, la moneda británica se hundió. "Soros se puso delante de un movimiento que estaba viniendo y le dio un último empujón», dice Argandoña. El Banco de Inglaterra gastó hasta 50.000 millones de dólares en los mercados de divisas para defender la libra sin éxito. La operación convirtió a Soros -hoy considerado un filántropo por su labor socialen símbolo de la especulación de la época. Para Solchaga, hoy un golpe así «no tiene posibilidades, porque ni Soros ni sus amigos tienen dinero suficiente para hundir el tipo de cambio de toda la eurozona».

Me pregunto si estos "golpes que no tienen posibilidades», si no tendrán algo que ver con la situación de Irlanda, Gracia y Portugal, así como la amenaza que se cierne sobre España, Italia, Bélgica y Francia, en suma sobre la moneda única europea: el euro. Pongo en

${ }_{3}$ MARs, A., El ataque que ganaron los especuladores. La tormenta financiera de los noventa llevó a una mayor cooperación monetaria, El PAIS, 1/10/2011. 
duda, sin que los términos puedan entenderse como peyorativos, que nuestra «lideresa» Ángela Merkel y su «paladín» Sarkozy, tengan la misma preocupación por la economía europea que por la economía de sus respectivos países y su eventual derrota en las próximas elecciones de las que depende su liderazgo. En la década de los noventa se hicieron muy populares los fondos de cobertura o fondos de inversión libre, conocidos como los hedge funds, que son un tipo de fondos de inversión colectiva que no están apenas sometidos a regulación, y que, precisamente por ello, han jugado un papel crucial en prácticamente todas las crisis financieras desde los años noventa, y, aprovechando la situación actual, siguen actuando en beneficio de los «bolsillos privados» de quienes los poseen y en perjuicio de los países y poblaciones que los componen.

La miseria moral de este tipo de actividades llega al punto de especular con las materias primas y las agrícolas, llevando a la muerte por hambre a millones de personas, sin importar que este «dinero de sangre» engrose la vanidad de unos pocos. Se pretende reprimir el tráfico de armas y de drogas, para evitar el enriquecimiento ilícito de un reducido grupo de personas a costa de la muerte de otros, del mismo modo se deja «campar por sus respetos» a otros traficantes de dinero que se definen como filántropos y que llevan la miseria, el dolor y la muerte a millones de personas, y todo esto basado en conceptos como «libertad y capital».

Se instala un nuevo capitalismo ${ }^{4}$, todavía más brutal y conquistador. Es el de una nueva categoría de fondos buitres, los private equities, fondos de inversión rapaces con apetito de ogro que disponen de capitales colosales (...) El fenómeno de estos fondos rapaces surgió hace quince años, pero estimulado por créditos baratos y a favor de la creación de instrumentos financieros cada vez más sofisticados, cobró en los últimos tiempos una dimensión preocupante. El principio es simple: un club de inversores afortunados decide comprar empresas a las que inmediatamente después administra de manera privada, lejos de la Bolsa y sus normas coactivas, y sin tener que rendir cuentas a accionistas puntillosos. La idea es eludir los principios mismos de la ética del capitalismo apostando exclusivamente a leyes de la jungla (...) Mientras personalmente ganan fortunas demenciales, los dirigentes de estos fondos practican, sin escrúpulos, los cuatro principios de la racionalización de las empresas; reducir el empleo, comprimir los salarios, aumentar los ritmos y deslocalizar.

${ }^{4}$ Ramonet, I., La Crisis del Siglo. El fin de una era del capitalismo financiero. Icaria Mas Madera, Barcelona 2009. 


\section{DARWINISMO SOCIAL, ANTÍTESIS DE LAS POLÍTICAS DE BIENESTAR SOCIAL}

Generalizar puede ser odioso, no obstante quisiera aportar una opinión general sobre los partidos políticos y sus propuestas. Nos prometen gobernar para todos sin distinción de quienes han votado a unas siglas u otras, se llega al poder con un contrato marco plasmado en los diferentes programas electorales, que luego nunca se cumplen, y que los ciudadanos nunca leen y como consecuencia desconocen las propuestas. La abstención aumenta, la desconfianza hacia los políticos aumenta y en el resto del electorado que participa, el voto parece que va más dirigido a las siglas y que en muchos casos están basados en filias y fobias, (en nuestro país posiblemente perduren en cierto grado las historias familiares pasadas de nuestra cruenta historia), esto puede indicar un compromiso con las siglas y no con las ideas y propuestas, y esto no debe significar que el pueblo sea «tonto», lo único que los ciudadanos quieren, es salir «adelante» en una sociedad cada vez más competitiva, acercar a sus hijos a situaciones de salud, avance económico y conocimiento, y esto resulta imposible sin un sistema político interventor, que regule y redistribuya la riqueza del estado e intervenga en los grandes desafíos que este mundo globalizado actual está provocando, intentado que lo que hoy es una amenaza para la seguridad y el bienestar de la población mundial, sea un camino por el que podamos transitar todos los ciudadanos con la esperanza de avanzar y no retroceder en los derechos inalienables de todos los seres humanos.

En la que ahora sabemos «aparente bonanza económica» se construía un gigante con pies de barro; en España se hablaba del pleno empleo, se desarrollaban política sociales avanzadas, conseguíamos superávit en las cuentas de la Seguridad Social, se asumía e intentaba integrar a numerosa población inmigrante, se ampliaban las pensiones, se aplicaban leyes sobre igualdad, es decir, en suma, se daba un gran paso hacia una política social integradora y con el marchamo básico del Estado de Bienestar, el gran reto y sueño que nos acercaba a los otros países de nuestro entorno, y que hacía que nuestro presidente de gobierno José Luis Rodríguez Zapatero, en el año 2004 afirmara que gobernaría para los más débiles, y en el 2008 que gobernaría pensando en los que no tienen de todo.

Después de grandes titubeos y negaciones, el siete de mayo de 2010 los jefes de Gobierno del Eurogrupo, el Fondo Monetario Internacional y los mercados financieros, hicieron que el presidente socialdemócrata español anunciara un plan de ajuste terriblemente im- 
popular: nueve millones de pensionistas, tres millones de funcionarios, cientos de miles de personas dependientes y medio millón de futuros padres sufrieron los recortes más amplios que conoce nuestro país y como consecuencia, y vistas las propuestas y actuaciones posteriores al 22 de marzo en las elecciones Autonómicas y Municipales así como las propuestas de recortes que posiblemente se tengan que seguir tomando, el sueño de alcanzar el Bienestar social, que siguiendo a Briggs ${ }^{5}$ podríamos definir: "como aquel en el que el poder organizado utiliza deliberadamente (a través de la política y la administración) mecanismos para modificar las fuerzas del mercado en tres importantes direcciones: primero garantizando ingresos minimos a los individuos y las familias, segundo eliminando niveles de inseguridad y evitando a los individuos y familias alcanzar cierto grado de "contingencia social" (por ejemplo enfermedad, envejecimiento o desempleo) que les permiten esquivar posibles crisis; $y$ tercero asegurando que todos los ciudadanos sin distinción alguna de estatus o clases social reciban los mejores niveles posibles de servicios sociales», empezó a tambalearse.

El Estado de Bienestar está amenazado por la especulación que se produce en lo que se ha dado en llamar «mercados»-posiblemente con la pretensión de no poner nombre propio a los especuladores-y en la inacción de los políticos y representantes de los ciudadanos que componen los grandes grupos G8 (la pertenencia al grupo no se basa en un criterio único, ya que no son ni los ocho países más industrializados, ni los de mayor renta per cápita ni aquellos con un mayor producto interior bruto); el G20 que está constituido por el G8, más once países recientemente industrializados, los llamados emergentes, de todas las regiones del mundo, y la Unión Europea como bloque económico, este último grupo se viene reuniendo desde 1999 a través de los jefes de Estado (o Gobierno), gobernadores de bancos centrales y ministros de finanzas. En este tipo de reuniones puede parecer que prima más «el sálvese el que pueda» que el interés general de la población mundial.

Las ideas de Darwin encontraron una enorme acogida en el campo de las ciencias sociales, que se plasmaron con el desarrollo del denominado darwinismo social de H. Spencer. Este movimiento postulaba, como algo natural de nuestra especie, una lucha por la existencia que conduciría al triunfo de los más aptos, definidos estos como aquellos que alcanzan un mayor éxito social y económico. Las diferencias de clase entre los individuos estaban marcadas y se ex-

${ }^{5}$ BRIggs, A., The Welfare State in Historical Perspective, en Pierson, CH, y Castles, F.G., The Welfare State Reader, Blakwwell. Cambridge, 2002. 
plicaban como la consecuencia de sus diferentes aptitudes, apoyando de esta forma las ideas del liberalismo económico; desde este momento estas ideas han sido la inspiración y el caldo de cultivo de aquellos que ansían la superioridad biológica de unos grupos sociales sobre otros, en muchas ocasiones hemos escuchado y/o leído estas propuestas en boca de los grandes prebostes de la especulación y el neoliberalismo especulativo, el "sueño americano» posiblemente hunde sus raíces en estas teorías.

\section{POLÍTICA SOCIAL Y CRISIS DE BIENESTAR SOCIAL}

La política social ${ }^{6}$ puede concebirse como una mediación entre lo que conviene desde un punto de vista político y lo que es posible según el cálculo económico, siempre bajo el monopolio de la acción pública. Desde el punto de vista económico, el mantenimiento del Estado de Bienestar va unido a la justificación de la propia intervención del sector público en la economía.

Posiblemente desde su creación como instrumento para escapar del dilema de la pobreza o la revolución, el Estado de Bienestar Social está en crisis, no obstante sirvió en su momento y sigue sirviendo, pues no existe una sociedad en la que prime la justicia social, sin una política social que tome medidas encaminadas a su consecución; no sirven de nada las leyes sin la posibilidad de su aplicación.

En 1986 en un reconocido y admirado libro sobre el Estado de Bienestar, «El Bienestar Social Acorralado» ${ }^{7}$, Demetrio Casado escribía: "A la vez sabemos que el déficit y la deuda externa que pesan sobre las economías estatales se oponen objetivamente a la decisión politica de incrementar el gasto público. De otra parte, sabemos que el Estado de bienestar presenta graves defectos. Su concepción y su aplicación están demandando correcciones importantes. Su basamento material o económico requiere serios ajustes a la coyuntura estructura actual. Al afrontar la necesidad de acrecentar el gasto público, hemos de plantearnos los citados defectos y desajustes (...) Habrá que comenzar por tomar nota de que las técnicas operativas o los instrumentos de la acción pro bienestar social presentan no pocos fallos. Probablemente, el más común y extendido es la burocratización de las instituciones de la política social (...) Habrá que atenerse a la circunstancia de que, dentro

\footnotetext{
${ }^{6}$ Freund, J., La cuestión social, Cuadernos de Trabajo Social, no 11, 1998.

7 Casado, D., El Estado de Bienestar Social Acorralado, Promoción Popular Cristiana, Madrid, 1986.
} 
del modelo socioeconómico vigente en el área occidental, las bases estratégicas del Estado social se están desmoronando. Como consecuencia de la crisis económica el pleno empleo, que aseguraba una demanda social moderada, y el crecimiento económico, que generaba excedentes para atenciones sociales, se han esfumado. Para mantener y ampliar la protección social se requiere, pues, una estrategia nueva».

En las fechas en las que el profesor Demetrio Casado escribía la cita anterior, España estaba en plena crisis y haciendo lo posible para no desmantelar nuestro incipiente Estado de Bienestar, que ya antes de su propio nacimiento estaba en entredicho, es revelador que el escrito citado sea tan actual, podría escribirse en este momento sin que por ello se notara las más de dos décadas transcurridas desde el mismo, en España el Estado de Bienestar Social que no ha terminado de construirse, ha estado y sigue estando amenazado, es como esos edificios a medio construir que vemos desde las carreteras y que la crisis del ladrillo dejó como esqueletos abandonados.

\section{LA INCERTIDUMBRE ANTE UNA INTERPRETACIÓN TEÓRICA CONSERVADORA DE LA CRISIS}

En una sociedad interdependiente y globalizada, se debate en la actualidad sobre la legitimación del poder, la intervención del estado en los mercados nacionales e internacionales cada vez más condicionados y determinados por los acontecimientos económicos, políticos y sociales que atenazan a las sociedades globales.

Hayek y Friedman como máximos representantes, entre otros, del pensamiento conservador ${ }^{8}$, "El neoliberalismo nace después de la Segunda Guerra Mundial, en Europa occidental y América del norte; refleja una vehemente reacción teórica y política contra el intervencionismo estatal y el estado de bienestar» postulan que el origen de la crisis del estado de bienestar se encuentra en el papel protagonista que la administración pública tiene en la sociedad civil, basándose en los siguientes argumentos:

En el excesivo gasto público, para compensar los desequilibrios sociales, que entre otros surgen como resultado de los desajustes del mercado, y que han provocado unas pérdidas masivas de empleo, lo que supone la disminución de los recursos públicos necesarios para el

${ }^{8}$ Houtart, F., Polit, F., El otro Davos. Globalización de resistencias y de luchas, Popular, Madrid, 2001. 
relanzamiento de la actividad productiva; del crecimiento de la burocracia estatal, debido a la expansión de los servicios sociales públicos, y del aumento de las subvenciones y subsidios a grupos marginales, realizados por el estado para evitar las situaciones de exclusión social, en suma en el excesivo gasto de recursos fiscales.

La falta de disciplina personal, ética y laboral necesarias para la continuidad y pervivencia del sistema capitalista, así como la tendencia igualitarista de las sociedades de bienestar han provocado la ruptura de los fundamentos sobre los que se mantiene la sociedad capitalista: la estructura social y las instituciones básicas, como la familia y el sistema educativo, que desarrollan funciones de socialización y de integración social. Esta crisis económica, social, cultural y de valores afecta a las instituciones públicas. El estado, en lugar de ser una institución neutral, está sometido a las presiones y al poder de los principales grupos sociales y económicos: sindicatos, organizaciones empresariales y partidos políticos. Como consecuencia de ello, propone una política de intervención mínima del sector público en materia social, cultural y educativa.

La sociedad Monte-Pelerin ${ }^{9}$, con las ideas neoliberales y Hayek a la cabeza, a partir del estallido de la gran crisis del modelo económico de la posguerra, en 1974, en la que el conjunto de los países capitalistas desarrollados entran en una profunda recesión, afirman que "las raíces de la crisis se hunden en el poder excesivo y nefasto de los sindicatos y de manera más general. Del movimiento obrero. Según ellos, los sindicatos han minado las bases de la acumulación privada (de las inversiones) por sus reivindicaciones salariales y por sus presiones de cara al aumento por el estado de los gastos sociales parasitarios. Estas presiones han disminuido los márgenes de ganancia de las empresas y han desencadenado procesos inflacionistas (alza de precios) que sólo pueden terminar en una crisis generalizada de las economías de mercado (...) El remedio es claro: mantener un Estado fuerte, capaz de aplastar la fuerza de los sindicatos y de controlar estrictamente la evolución de la masa monetaria (política monetarista). Este Estado debe, además, ser frugal en el terreno de los gastos sociales y abstenerse de intervenciones económicas. La estabilidad monetaria debe constituir el objetivo supremo de todos los gobiernos».

Del mismo modo y sirva como ejemplo en palabras de Milton y Rose Friedman ${ }^{10}$, sobre la enseñanza. «La televisión, la quiebra de la fa-

9 Houtart, F., Polit, F., op. cit., p. 16.

10 Friedman, M., y R., La Tiranía del Statu Quo, Ariel. Barcelona 1984. 
milia, así como otros cambios culturales de décadas recientes, se consideran las causas responsables del deplorable nivel de nuestras instituciones públicas de enseñanza. Indudablemente, estos factores han contribuido al deterioro del sistema educativo, pero no son las causas principales en nuestra opinión, las razones fundamentales del deterioro son la centralización y la burocratización de la enseñanza pública. A medida que la financiación de las escuelas públicas ha ido escapando progresivamente del control local, la burocracia de la enseñanza ha tendido a sustituir a los padres en cuanto a lo que nuestros hijos deben aprender y como. El medio más práctico, y quizás el único, de devolver el control a los padres es introducir un cambio mediante el cual los padres puedan elegir los centros a los que sus hijos deben asistir y (si no están satisfechos) que puedan trasladar a sus hijos a otro centro (...) Es muy deseable que todos los jóvenes, independientemente de la riqueza o la religión o el color o el nivel social propios de su familia, tengan la oportunidad de recibir cuanta instrucción puedan asimilar, siempre que estén dispuestos a pagarla, bien en el momento, o bien a costa de las rentas superiores que después percibirán, gracias a la instrucción recibida. Sería muy defendible la concesión de préstamos o equivalentes con dinero público, en caso necesario. Pero no nos parece defendible la pura subvención».

Por el contrario y como consecuencia el Programa de las Naciones Unidas para el Desarrollo (PNUD) que inició la publicación del Informe sobre Desarrollo Humano en 1990, se expuso claramente el concepto de desarrollo humano. El primer capítulo, «Definición y medición del desarrollo humano", comienza con la siguiente declaración que no deja lugar a dudas: "La verdadera riqueza de una nación está en su gente. El objetivo básico del desarrollo es crear un ambiente propicio para que las personas disfruten de una vida prolongada, saludable y creativa. Ésta puede parecer una verdad obvia, aunque con frecuencia se olvida debido a la preocupación inmediata de acumular bienes de consumo y riqueza financiera».

En el año 2006 el (PNUD) ${ }^{11}$ señalaba que: «El aumento de la disparidad del rendimiento económico está creando dos mundos, cada vez más polarizados (...) Hay en el mundo 358 personas cuyos activos se estiman en más de mil millones de dólares cada una, con lo cual superan el ingreso anual combinado de países donde vive el $45 \%$ de la población mundial».

En este mismo informe y en relación a los dirigentes políticos se refería que: «Los dirigentes políticos suelen estar fascinados por los as-

11 PNUD, Informe sobre desarrollo humano, 2006. 
pectos cuantitativos del crecimiento económico. Es necesario que se preocupen más de su estructura y de su calidad. A menos que los gobiernos adopten oportunamente medidas correctivas, el crecimiento económico puede quedar distorsionado y ser defectuoso. Es necesario hacer decididos esfuerzos para evitar el crecimiento sin empleo, sin raíces, sin equidad, sin voz de las comunidades y sin futuro».

\section{RESPUESTA ANTE LA CRISIS. POLÍTICAS SOCIALES ACTIVAS EN BIENESTAR SOCIAL}

La negativa a una apuesta decidida por el favorecimiento del progreso social, hace que la democracia pierda sentido y credibilidad.

Los mercados desregularizados ${ }^{12}$ "sólo existen en la fantasía de los economistas puros. A fin de cuentas tales mercados no serán autorregulados sino explotados. En realidad los mercados funcionan porque están regulados, la cuestión es saber por quién y para el beneficio de quién (...) En los países ricos y poderosos, de tradición parlamentaria estable, el neoliberalismo alimenta una peligrosa deriva hacia lo que se podría calificar como "democracia de baja intensidad", una alternativa sin alternativas ya que, no importa si se vota en blanco, verde, azul o rojo, la suerte del votante no depende del gobierno escogido, sino de las vicisitudes del mercado, de las estrategias (secretas) de los oligopolios, de las decisiones de un banco central (independiente de los ciudadanos, pero no de los mercado financieros».

Para cobijarse de la lluvia entre otros se utiliza un paraguas o se protege de la misma pasando al interior de un edificio, desde estas páginas se defiende que para guarecerse de la crisis que nos asola, es necesario cobijarse por medio de políticas sociales activas que fomenten el empleo, la educación y la salud, así como una coordinación de respuestas en materia económica coherentes a nivel global, ordenadas alrededor de alternativas constructivas.

Se podría definir el Estado de Bienestar ${ }^{13}$ como «el conjunto de actuaciones públicas tendentes a garantizar a todos los ciudadanos de una nación, por el hecho de serlo, el acceso a un mínimo de servicios que garanticen su supervivencia (entendida en términos sociales y no estrictamente biológicos)».

${ }^{12}$ Houtart, F., Polit, F., op. cit., p. 33.

13 Muñoz de Bustillo, R., Crisis y futuro del Estado de Bienestar, Alianza Universidad, Madrid, 1989. 
Son los objetivos básicos del Estado de Bienestar: el derecho político a un mantenimiento de un estándar de vida para todos los ciudadanos; una política de redistribución de las rentas por medio de un reparto equitativo de la transferencia de impuestos y a través de la provisión publica de determinados bienes que cubran las necesidades básicas de los ciudadanos, siendo los bienes preferentes la educación y la sanidad, del mismo modo y como objetivo básico, se debe plantear la lucha por la integración social y la lucha contra la pobreza surgida como consecuencia de la crisis económica, y que afectan al desempleo de larga duración, precariedad en el empleo, economía sumergida, desregulación de las relaciones laborales, los procesos de feminización de la pobreza, los cambios sociales y demográficos, el envejecimiento del envejecimiento, la proliferación de familias monoparentales o la falta de integración de la población inmigrante. Una democracia sin derechos no es democracia.

Desde el punto de vista económico ${ }^{14}$, el mantenimiento del Estado de Bienestar va unido a la justificación de la propia intervención del sector público en la economía, la cual, y como con anterioridad hemos visto, no está exenta de críticas. De igual modo que los fallos del mercado han servido de argumentos a favor de una mayor presencia pública en la vida económica, los fallos del sector público minan las bases que sustentan la legitimidad de la presencia de éste en la vida de los ciudadanos. La respuesta que habitualmente se realiza ante esta última situación es la privatización de servicios.

Es difícil comprender que sea más fácil gestionar de forma adecuada un servicio público desde la esfera de lo privado, cuyo objetivo como el de cualquier otro inversor es obtener beneficios económicos a corto, medio y largo plazo, que gestionarlo mediante profesionales contratados y que han superado pruebas que demuestran sus destrezas en tales menesteres. La experiencia ha puesto de manifiesto, tomando como ejemplo las áreas de salud, que determinadas actuaciones clínicas son de alto coste económico y que las entidades privadas no son capaces de rentabilizar, ante esta situación derivan estos casos a la sanidad pública, es decir, las actividades de alto coste los paga la sanidad pública y las de bajo coste la sanidad privada, esto no puede indicar una «mejor» gestión de la salud, sino que parece más bien señalar un aprovechamiento de los impuestos que revierten en el sistema de salud público en beneficio de los inversores de la salud privada. Posiblemente no es cuestión de una inadecuada praxis profe-

${ }^{14}$ Alemán, C. (coordinadora). Políticas Sociales, Thomson Reuters, Pamplona, 2009. 
sional en el ámbito público, sino de una gestión inadecuada de los responsables de los mismos.

En el área de salud se está planteando el copago. En momentos de crisis como la actual podría tener sentido dicho planteamiento, sino fuera porque sería tanto como aceptar que una vez que hemos pagado por un servicio mediante nuestros impuestos, se nos exija que abonemos otra cantidad más por el mismo dando lugar a una duplicidad en el pago.

En la actualidad millones de personas que perciben sueldos llamados «mileuristas» pagan por los productos farmacéuticos un 40\% de su valor de origen, mientras que pensionistas que perciben rentas por encima de esos valores tienen las medicinas de forma gratuita. Este pretende ser un ejemplo de los retos que los responsables de marcar las pautas impositivas podrían tomar en cuenta. Desde esta perspectiva, los límites del Estado de Bienestar ${ }^{15}$ vendrían condicionados por los límites fiscales de la propia dimensión del gasto público y habrían dado lugar a lo que se da en llamar «crisis fiscal del Estado».

Siguiendo a este mismo autor, señalar que la crisis fiscal del Estado se produce como consecuencia de tres hechos concurrentes:

El capital monopolista socializa cada vez más los costes del capital y los gastos de producción, pero no los beneficios, ya que estos tienden a concentrarse en determinados colectivos.

Los costes salariales suben más que la productividad en el sector estatal como consecuencia del componente inercial de los mismos y de su tendencia a la imitación de lo que sucede en el sector privado, sin que en muchas ocasiones sea posible, ya no sólo comprobar la evolución de la productividad de los factores empleados, sino ni siquiera medirla.

El Estado debe cubrir las crecientes necesidades sociales que el capital no cubre, por lo que se produce un incremento del número de personas dependientes del Estado. Es este el que debe subvenir a las necesidades crecientes de sus ciudadanos, liberando a la previsión individual o a la familia de hacerlo.

La pérdida de legitimidad de la acción pública conduce a la ruptura del consenso social, pilar fundamental del Estado de Bienestar, y que se había mantenido desde la postguerra hasta la crisis de los se-

15 O'Connor, La crisis fiscal del Estado. Península, Madrid, 1981. 
tenta y en la actualidad. Se podría afirmar que la actual crisis del Estado de Bienestar procede, en gran medida, de su falta de adaptación a los nuevos problemas que surgen de las cambiantes estructuras sociales.

Es conveniente defender unos límites razonables del Estado de Bienestar que eviten el sesgo de tener que delimitarlo, según las fases del ciclo económico y que obedezcan, sobre todo, a criterios de racionalidad y de eficiencia económica.

\section{CONCLUSIONES}

En los momentos actuales podríamos situar la crisis, no como el resultado único e inevitable de la inestabilidad propia de los mercados financieros desregulados, sino como el efecto de la falta de honradez y de la irresponsabilidad de algunos agentes financieros mal controlados por los poderes públicos.

La incapacidad del mercado de resolver de forma satisfactoria las cuestiones que afectan a las necesidades de los ciudadanos, da paso a la exigencia de una acción pública orientada a corregir el reparto de renta que suministra el mercado, es decir a la política redistributiva.

Se debe reclamar la función pública de la política, actividad que debe buscar el bien común de la población sobre la que se "gobierna» sin menoscabar la «integridad moral» de las personas que la componen. No es lo mismo un político corrupto que el que no lo es, no se puede generalizar con los apropiados intentos de gestionar un cambio social para el progreso económico y social, con los que únicamente buscan el beneficio propio a cambio de las «migajas de la corrupción» a propios y subalternos.

Posiblemente desde su creación como instrumento para escapar del dilema de la pobreza o la revolución, el estado de bienestar social está en crisis, no obstante sirvió en su momento y sigue sirviendo, no existe una sociedad en la que prime la justicia social, sin una política social que tome medidas encaminadas a su consecución; no sirven de nada las leyes sin la posibilidad de su aplicación.

La crisis económica acrecienta la pobreza y la marginalidad, a la vez que reduce los recursos necesarios para la financiación de la política social. Las prestaciones y servicios para el bienestar social, se comprimen y reducen, a la vez que se desarrolla una intensa cam- 
paña de preparación mental, cuyo mensaje principal es el desmantelamiento y cuestionamiento del propio sistema.

En una sociedad interdependiente y globalizada, se debate en la actualidad sobre la legitimación del poder, la intervención del estado en los mercados nacionales e internacionales cada vez más condicionados y determinados por los acontecimientos económicos, políticos y sociales que atenazan a las sociedades globales.

Sea como fuere, el debate está en los papeles y en la realidad cotidiana de millones de personas, se reconoce que el papel de los mercados financieros y su intensa desregulación ha sido el eje vertebrador de la profunda crisis por la que estamos pasando, la especulación, la desunión de los representantes políticos y el más que posible mensaje que se lanza sobre los «mercados» del «sálvese el que pueda» está produciendo un grado de desconfianza en los mismos, que abocan a que se esté denominado a esta crisis, como una «crisis de confianza». La larga duración que se prevé de la misma, y los estragos que se están produciendo sobre el mercado laboral y como consecuencia del consumo y generación de riqueza, requieren medidas inmediatas y consensuadas entre los países y agentes sociales, que mitiguen las desigualdades entre los ciudadanos, volvamos o no a las medidas Keynesianas, lo que si es necesario es hacer "algo», la inacción esta abocando a que esta crisis se alargue en el tiempo y haga renacer reivindicaciones que en algunos casos pueden convertirse en violentas, situación que hasta el momento no se está produciendo.

\section{BIBLIOGRAFÍA}

Alemán, C. (coordinadora). Políticas Sociales, Thomson Reuters. Pamplona, 2009.

Askenazy, P.; Coutror, T.; Orléan, A.; Sterdyniak, H. Manifiesto de economistas aterrados, Madrid, 2011.

Briggs, A., The Welfare State in Historical Perspective, en Pierson, $\mathrm{CH}$, y CAstles, F.G., The Welfare State Reader, Blakwwell. Cambridge, 2002.

Casado, D., El Estado de Bienestar Social Acorralado, Promoción Popular Cristiana, Madrid, 1986.

Freund, J., La cuestión social, Cuadernos de Trabajo Social, n ${ }^{\circ} 11$, 1998. 
Friedman, M. y R., La Tiranía del Statu Quo, Ariel, Barcelona 1984.

Houtart, F., Polit, F., El otro Davos. Globalización de resistencias y de luchas, Popular, Madrid, 2001.

MARs, A., El ataque que ganaron los especuladores. La tormenta financiera de los noventa llevó a una mayor cooperación monetaria, El PAIS, 1/10/2011.

Mochón, F., Economía teoría y política, McGraw-Hill, Madrid, 1995.

Muñoz de Bustillo, R., Crisis y futuro del Estado de Bienestar, Alianza Universidad, Madrid, 1989.

O’Connor, La crisis fiscal del Estado, Península, Madrid, 1981.

PNUD, Informe sobre desarrollo humano, 2006.

Ramonet, I., La Crisis del Siglo. El fin de una era del capitalismo financiero, Icaria Mas Madera, Barcelona 2009. 
